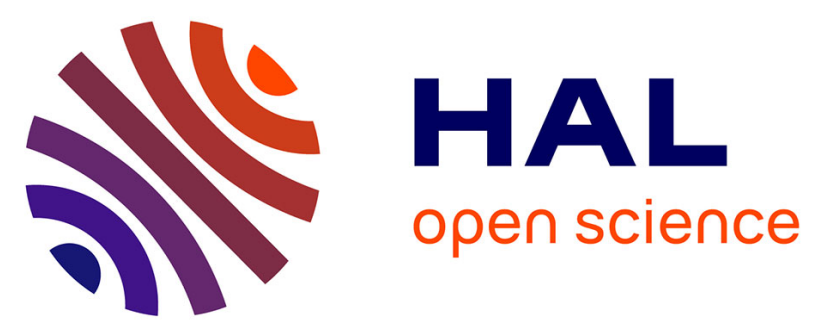

\title{
Synthesis and evaluation of naphthoic acid derivatives as fluorescent probes to screen advanced glycation end-products breakers
}

Luc Séro, François Calard, Lionel Sanguinet, Eric Levillain, Pascal Richomme, Denis Seraphin, Séverine Derbré

\section{To cite this version:}

Luc Séro, François Calard, Lionel Sanguinet, Eric Levillain, Pascal Richomme, et al.. Synthesis and evaluation of naphthoic acid derivatives as fluorescent probes to screen advanced glycation endproducts breakers. Bioorganic and Medicinal Chemistry Letters, 2012, 22 (21), pp.6716 - 6720. 10.1016/j.bmcl.2012.08.092 . hal-03027816

\section{HAL Id: hal-03027816 \\ https://univ-angers.hal.science/hal-03027816}

Submitted on 27 Nov 2020

HAL is a multi-disciplinary open access archive for the deposit and dissemination of scientific research documents, whether they are published or not. The documents may come from teaching and research institutions in France or abroad, or from public or private research centers.
L'archive ouverte pluridisciplinaire HAL, est destinée au dépôt et à la diffusion de documents scientifiques de niveau recherche, publiés ou non, émanant des établissements d'enseignement et de recherche français ou étrangers, des laboratoires publics ou privés. 


\title{
Synthesis and evaluation of naphthoic acid derivatives as fluorescent probes to screen advanced glycation end-products breakers
}

\author{
Luc Séro $^{\mathrm{a}, \mathrm{b}}$, François Calard ${ }^{\mathrm{b}}$, Lionel Sanguinet ${ }^{\mathrm{b}}$, Eric Levillain ${ }^{\mathrm{b}}$, Pascal Richomme ${ }^{\mathrm{a}}$, Denis Séraphin ${ }^{\mathrm{a}}$, \\ Séverine Derbré ${ }^{\mathrm{a}, *}$
}

a PRES LUNAM, Université d'Angers, EA 921 SONAS, SFR 4207 QUASAV, 16 bd Daviers, 49045 Angers, Cedex 01, France

b PRES LUNAM, Université d'Angers, MOLTECH-Anjou, CNRS UMR-6200, 2 bd Lavoisier, 49045 Angers, Cedex 01, France

\section{A R T I C L E I N F O}

\section{Article history:}

Received 10 July 2012

Revised 23 August 2012

Accepted 25 August 2012

Available online 3 September 2012

\section{Keywords:}

Advanced glycation end products

AGEs breakers

Assay

Fluorescent probes

Naphthoic acid

\begin{abstract}
A B S T R A C T
Advanced glycation end-products, namely AGEs, are involved in the pathogenesis of numerous diseases. If AGEs inhibitors are well-known, only few products are described as compounds able to destroy those deleterious products. In this work, we describe naphthoic acid derivatives, particularly 1-(naphthalen-1yl)propane-1,2-dione $\mathbf{9}$, allowing the simple and rapid detection of AGEs breakers using a 96-well microplate fluorescence assay. Since the inaugurate publication about AGEs breakers whose activity was demonstrated using HPLC analysis, this work proposes the first assay suitable for automated and high throughput screening of AGEs breakers.
\end{abstract}

(ㄷ) 2012 Elsevier Ltd. All rights reserved.
Advanced glycation end-products, namely AGEs, are involved in the pathogenesis of diabetes ${ }^{1,2}$ and neurological diseases like the Alzheimer's disease. ${ }^{3}$ They also contribute to the development of atherosclerosis, ${ }^{4}$ joint diseases ${ }^{5}$ and cause aging of many tissues. ${ }^{6}$ Molecules able to break AGEs or inhibit their formation may thus be considered as potential drugs, dietary supplements or other bioactive ingredients. ${ }^{7-9}$ These considerations have thus prompted the scientific community to identify advanced glycation end-products inhibitors or breakers. The Maillard reaction is non-enzymatic, and divided in two stages: the early stage consists in reaction between the carbonyl group of a reducing sugar and the primary amino groups of a protein (lysine, arginine) ${ }^{10,11}$ and produces the corresponding Schiff base, which undergoes an Amadori rearrangement. Then complex oxidation, dehydration and condensation reactions lead, via intra- and intermolecular crosslinking of the proteins, to AGEs. AGEs inhibitors and breakers act either through trapping of reactive dicarbonyl species, preventing oxidation using transition metal chelators or free radical scavengers, or breaking AGEs cross-linking. ${ }^{7}$ One can consider AGEs breakers as compounds able to cleave the $\alpha$-dicarbonyl compounds resulting from crosslinking reactions between post-Amadori products and nucleophilic functions (i.e. Lys, Arg, Cys) of proteins. ${ }^{12}$

Since Vinson and Howard publication fifteen years ago, ${ }^{13} \mathrm{chem}-$ ical procedures to screen AGEs inhibitors were developed. ${ }^{8,14}$ How-

\footnotetext{
* Corresponding author.

E-mail address: severine.derbre@univ-angers.fr (S. Derbré).
}

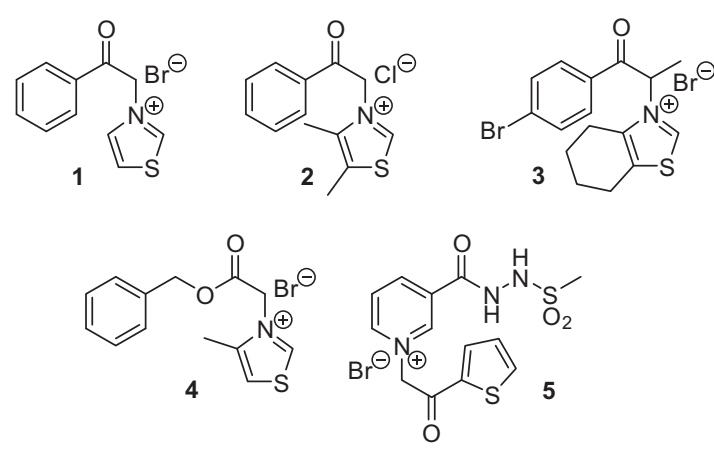

Figure 1. Examples of AGEs breakers described in literature.

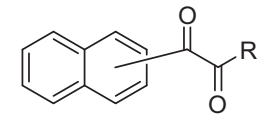

Non fluorescent probe

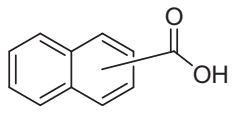

Fluorescent dye
Figure 2. Formation of a fluorescent naphthoic acid from the reaction between a non-fluorescent probe and an AGEs breaker.

ever, to our knowledge the sole publication relating a nonbiological method to identify AGEs breakers was published in 


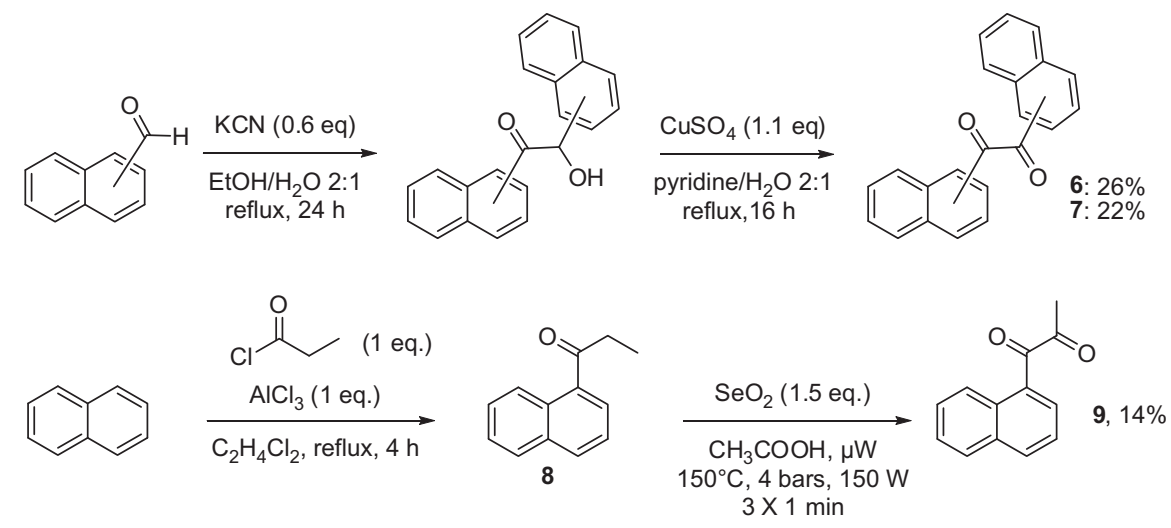

Figure 3. Synthesis of non fluorescent naphthyl dicarbonylated probes 6, 7 and $\mathbf{9 .}$

1996 by Vasan et al. It requires high performance liquid chromatography (HPLC) analysis and consisted in quantification of benzoic acid formed by 1-phenyl-1,2-propanedione (22 mM) disruption. The yield of benzoic acid was calculated by area integration $(254 \mathrm{~nm})$ and interpolation from a standard curve obtained by injection of standard amounts of pure benzoic acid. ${ }^{12}$ It is not suitable for high throughput screening (HTS) of new pharmacophores. This could explain the poor diversity of structures described as
AGEs breakers in literature: most of them are derivatives of the lead compound phenacylthiazolium bromide $\mathbf{1}$ (PTB) such as alagebrium 2 (formerly known as ALT-711), C16 3 or C36 4; pyridinium derivatives were also described such as TRC4149 5 (Fig. 1). ${ }^{15-18}$ So we embarked upon the conception and synthesis of a probe suitable for HTS of AGEs breakers.

Fluorescence probes are often used by researchers in HTS to detect particular changes or components as fluorescence allows
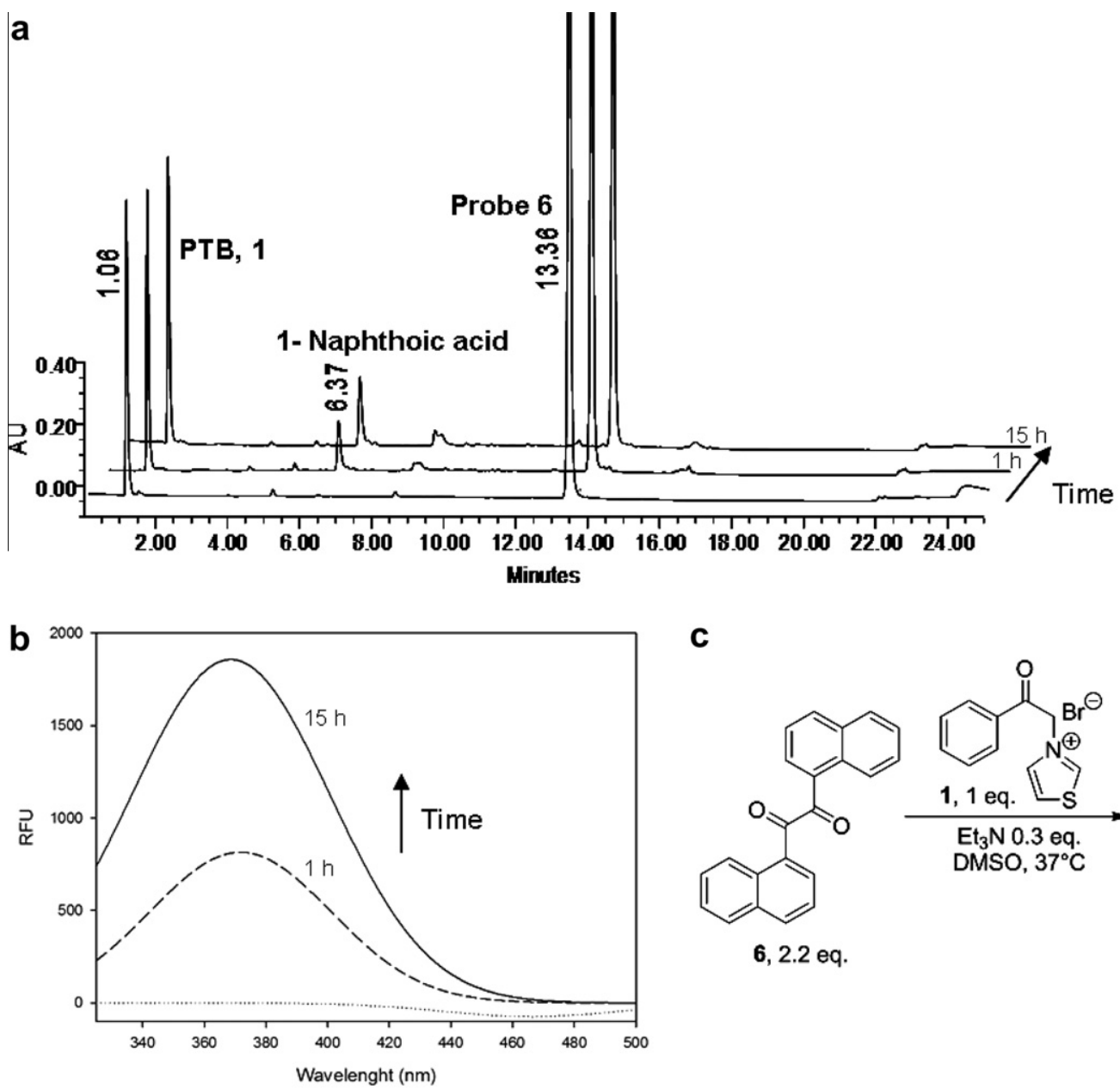

C

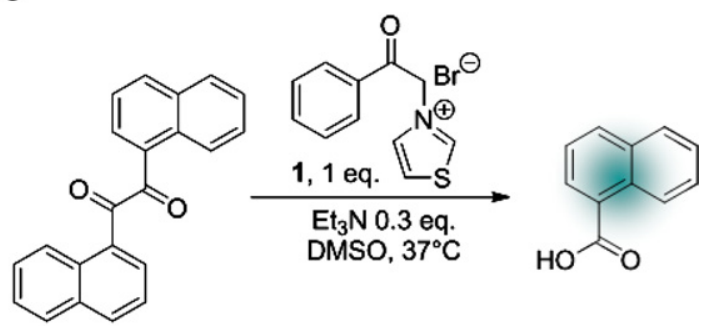

6, 2.2 eq.

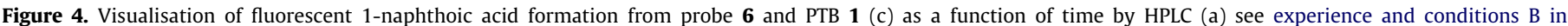

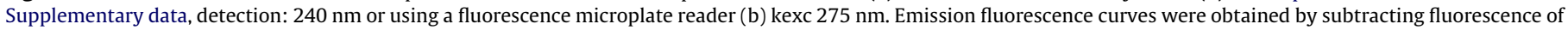
the mixture with Et $3 \mathrm{~N}$ minus the one of the mixture without Et $3 \mathrm{~N}$, see experimental part. 


\section{a}

\section{1- Naphthoic acid}
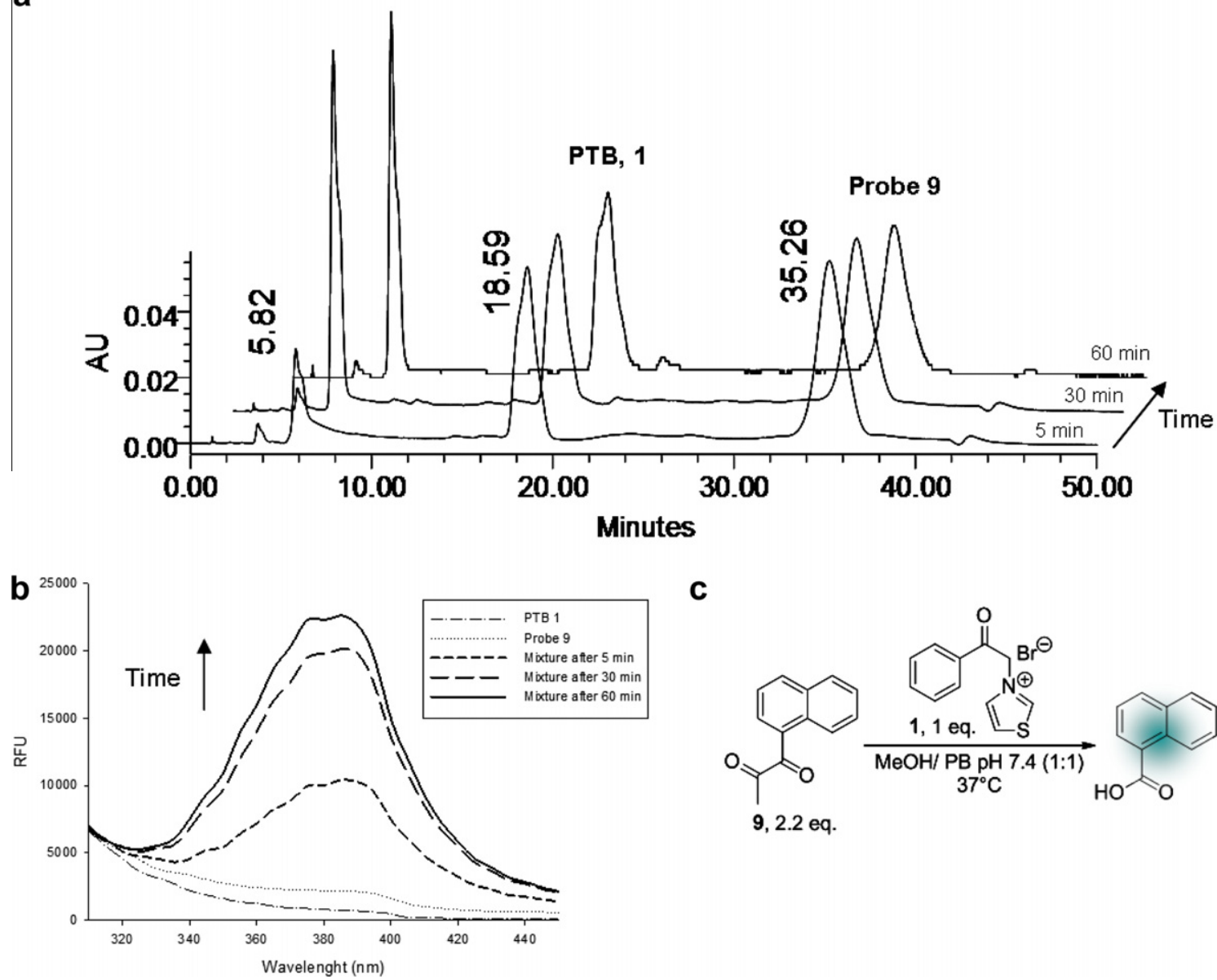

C

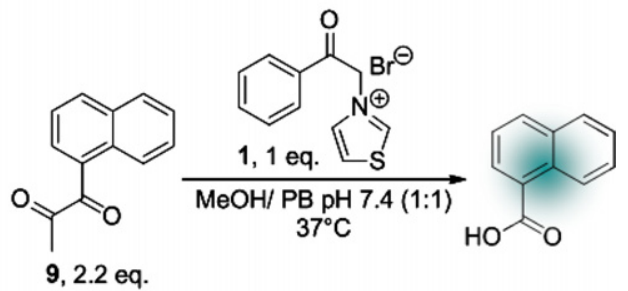

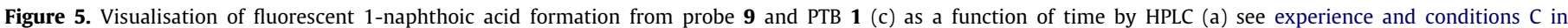
Supplementary data, detection $280 \mathrm{~nm}$ or using a fluorescence microplate reader (b) kexc $280 \mathrm{~nm}$.

sensitive and selective measurements. ${ }^{19}$ Even if naphthalene-based dyes are sensitive to the environment and exhibit weak fluorescence in aqueous media, those molecules tend to have an emission spectra and are used as fluorescent probes (e.g. dansyl chloride, 8anilino-1-naphthalenesulfonic acid). ${ }^{19}$ Our project aimed at synthesizing a non-fluorescent $\alpha, \beta$-dicarbonyl probe able to form a fluorescent carboxylic acid when an AGEs breaker is added. As 1and 2-naphthoic acids derivatives were previously described as fluorophores, ${ }^{20-23}$ our efforts were directed toward the synthesis and evaluation of $\alpha, \beta$-dicarbonylated compounds suitable to react with AGEs breakers to form fluorescent naphthoic acids (Fig. 2).

Our project began by synthesizing symmetric dimers $\mathbf{6}$ and 7 , 'respectively' from 1 and 2-naphtaldehydes using a method previously described by Bailey et al. to obtain 1,2-diones from corresponding aldehydes (Fig. 3). ${ }^{24}$ The potential of probes $\mathbf{6}$ and $\mathbf{7}$ to detect AGEs breakers was then evaluated with the reference compound PTB 1. More precisely, degradation by PTB 1 of probes 6 and 7 into 1- and 2-naphthoic acids 'respectively' was evaluated using both HPLC as earlier reported ${ }^{12,25}$ and fluorescence measurement. In their articles, Vasan et al. ${ }^{12}$ and Thornalley and Minhas ${ }^{25}$ studied 1-phenyl-1,2-propanedione cleavage in a mixture of methanol and phosphate buffer. However due to insolubility of probes $\mathbf{6}$ and $\mathbf{7}$ in such media, the formation of corresponding naphthoic acids using PTB 1 as a breaker was first attempted in a mixture of DMSO and phosphate buffer (see experimental part, conditions A). Traces of naphthoic acids were detected after $24 \mathrm{~h}$ at $37^{\circ} \mathrm{C}$ by HPLC-DAD and with a fluorescence microplate reader by comparison with commercial sample (data not shown). As dimeric probes were poorly soluble with water as a cosolvent, DMSO was used as the sole solvent. However no reaction occurred. We then thought that $\alpha, \beta$-dicarbonyl probes cleavage might be accelerated under basic conditions. Indeed PTB 1 is thought to cleave $\alpha, \beta$-dicarbonyl as thiamine diphosphate does: $\mathrm{C} 2$ of thiazole ring can be deprotonated by a base to give a nucleophilic carbanion that can then react with electrophiles. ${ }^{12,26}$ Thus we postulated that basic conditions would promote the formation of a ionized and stronger nucleophile from PTB 1 leading to enhanced formation of expected fluorescent species. As depicted in Figure 4, in presence of triethylamine, 1-naphthoic acid was produced from PTB 1 and $\alpha, \beta$-dicarbonyl probe $\mathbf{6}$ after only $1 \mathrm{~h}$ at $37^{\circ} \mathrm{C}$. This was observed using both HPLC-UV (Fig. 4a) and measurement of fluorescence emission spectrum (Fig. 4b). Same results were observed using probe 7 (data not shown). However, the conditions required by an assay using those dimeric probes seemed inappropriate to the selection of potential drugs by a high throughput screening: even if naphthoic acids were produced from corresponding probes and fluorescence detected, reaction yields were very low and should be improved; triethylamine use in such an assay seemed also inappropriate and should be replaced by water.

As previously explained, dimeric probes were only soluble in DMSO and a precipitate occurred when water was added to the mixture. This prompted us to develop a second generation of water soluble probes with less steric hinderance. Indeed formation of fluorescent naphthoic acids from probes 6 or 7 was quite slow 
a

\section{1- Naphthoic acid}
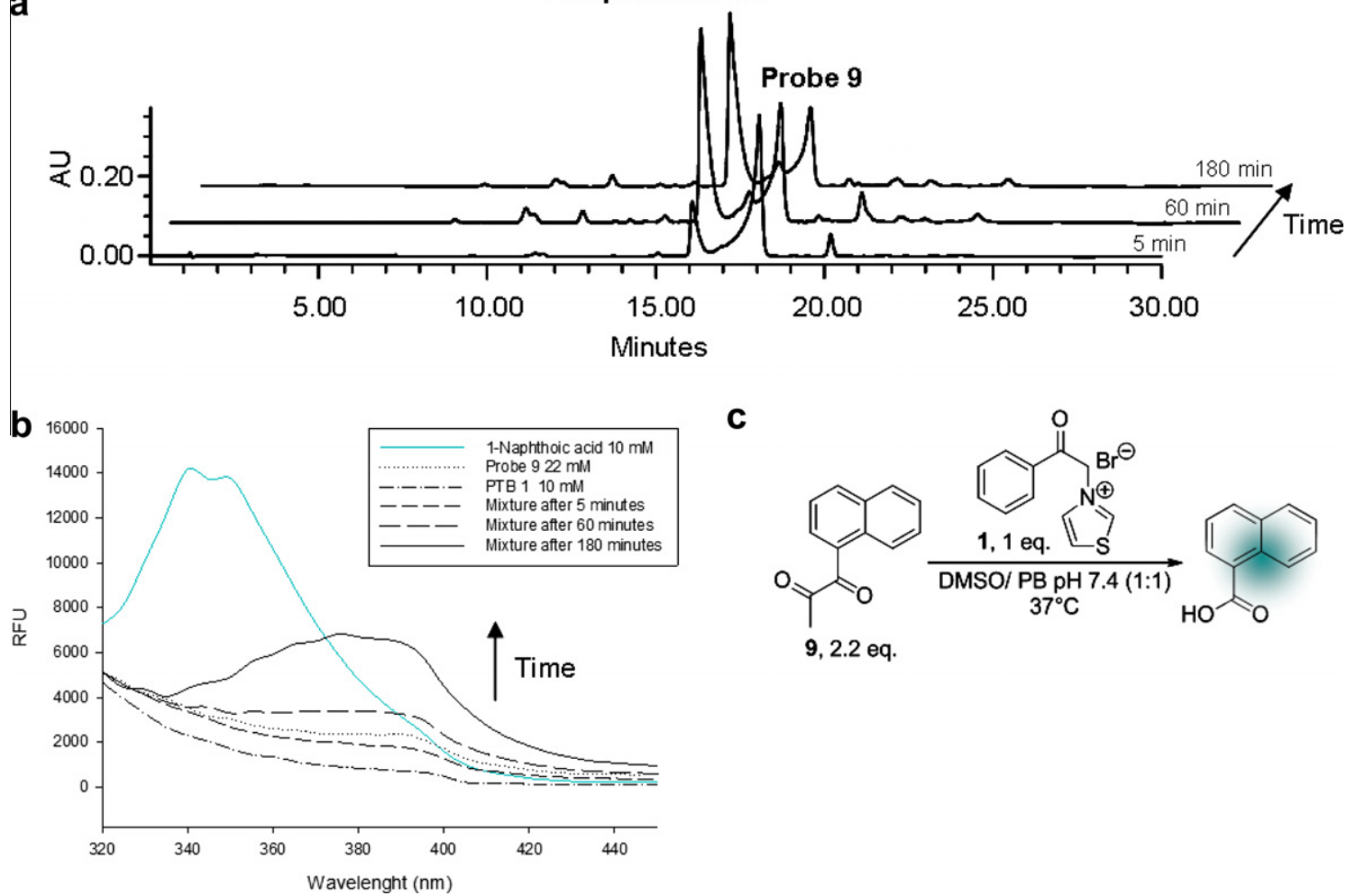

C

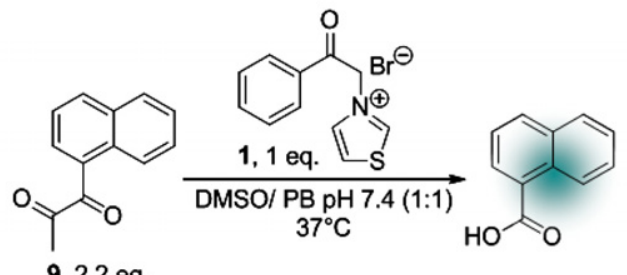

9, $2.2 \mathrm{eq}$

Supplementary data, detection: $310 \mathrm{~nm}$ or using a fluorescence microplate reader (b) kexc $280 \mathrm{~nm}$.

since about $24 \mathrm{~h}$ were necessary to achieve the maximum fluorescent signal. This long reaction time may not be suitable for all AGEs breakers as a rapid hydrolysis of PTB $\mathbf{1}$ was previously reported by Thornalley and Minhas. ${ }^{25}$ Therefore the second generation of probes should react rapidly to form corresponding fluorescent naphthoic acids. Thus, inspired by 1-phenyl-1,2-propanedione used by Vasan et al. in their inaugurate publication on AGEs breakers, we chose a naphthyl-1,2-propanedione as a target compound. ${ }^{12}$ As shown in Figure 3 , through a Friedel-Craft acylation from naphthalene and propionyl chloride, the corresponding ketone was obtained and further oxidized by selenium oxide under microwaves irradiation to form expected probe $\mathbf{9}$.

First, as depicted on Figure 5, the assay was conducted in $\mathrm{MeOH} /$ phosphate buffer: ${ }^{12,25}$ 1-naphthoic acid formation from probe 9 was detected after only 5 min using HPLC as well as a fluorescence microplate reader. As described for 1-phenyl-1,2-propanedione by Vasan et al., using these conditions, only 30 min were necessary to reach a maximum of fluorescence corresponding to a quantitative reaction between PTB 1 and probe 9. ${ }^{27}$ However we aimed at developing a probe suitable for high throughput screening, we also performed the reaction with a mixture of phosphate buffer and DMSO. Replacement of $\mathrm{MeOH}$ by DMSO could help us to solve solubility problems encountered with a large diversity of tested molecules. It will also avoid the uncontrolled evaporation of $\mathrm{MeOH}$ occurring at $37^{\circ} \mathrm{C}$.

As shown on Fig. 6, similar results were obtained in DMSO/PB (1:1). The reaction was a bit slower but was completed after $3 \mathrm{~h}$.

The identity of 1-naphthoic acid obtained from probe 9 degradation was checked on line using LC-DAD-MS and by NMR after purification (data not shown). However as shown on Fig. 6b, emission fluorescence spectrum of compound formed from probe 9 seemed different from the one of 1-naphthoic acid. In fact, as

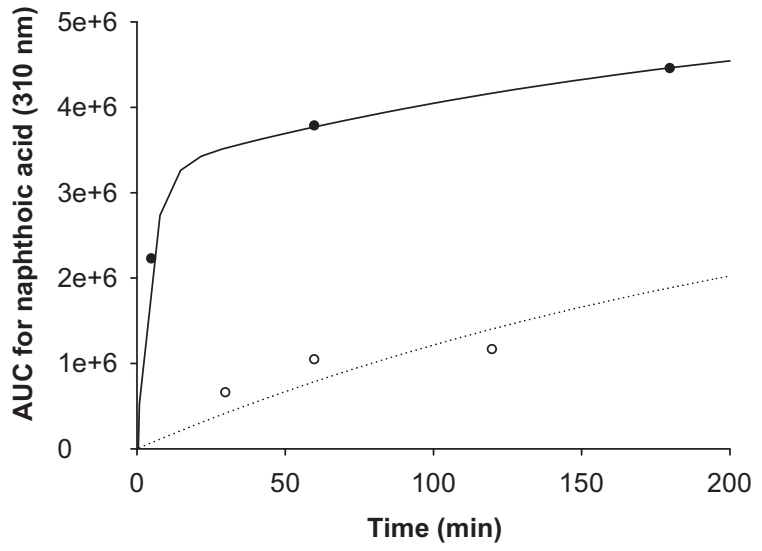

Figure 7. Formation of 1-naphthoic acid from probe $\mathbf{9}$ in DMSO/PB as a function of time with (solid) or without (dotted) any AGEs breaker (see conditions D in experimental part, detection: $310 \mathrm{~nm}$ ): Area under curve (AUC) for 1-naphthoic acid $\left(t_{\mathrm{R}}=15.9 \mathrm{~min}\right)$ depicted as a function of time shows a partial spontaneous degradation of probe $\mathbf{9}$ in aqueous media but 1-naphthoic acid formation from probe $\mathbf{9}$ occurs faster and with a best yield with PTB 1.

previously described by Thornalley and Minhas, ${ }^{25} \mathrm{pH}$ decreased from 7.4 to 5-6 after $4 \mathrm{~h}$. This was due to the rapid hydrolysis of PTB 1, consuming one equivalent of hydroxide ions. Fluorescence emission spectrum of 1-naphthoic acid performed in DMSO/PB pH 5.6 indicated a maximum around $380 \mathrm{~nm}$ as observed in our assay.

To ensure that the formation of 1-naphthoic acid from probe $\mathbf{9}$ was due to PTB 1 and not spontaneous, probe $\mathbf{9}$ was incubated at $37^{\circ} \mathrm{C}$ for $24 \mathrm{~h}$ in a mixture DMSO/PB without any AGEs breaker. 


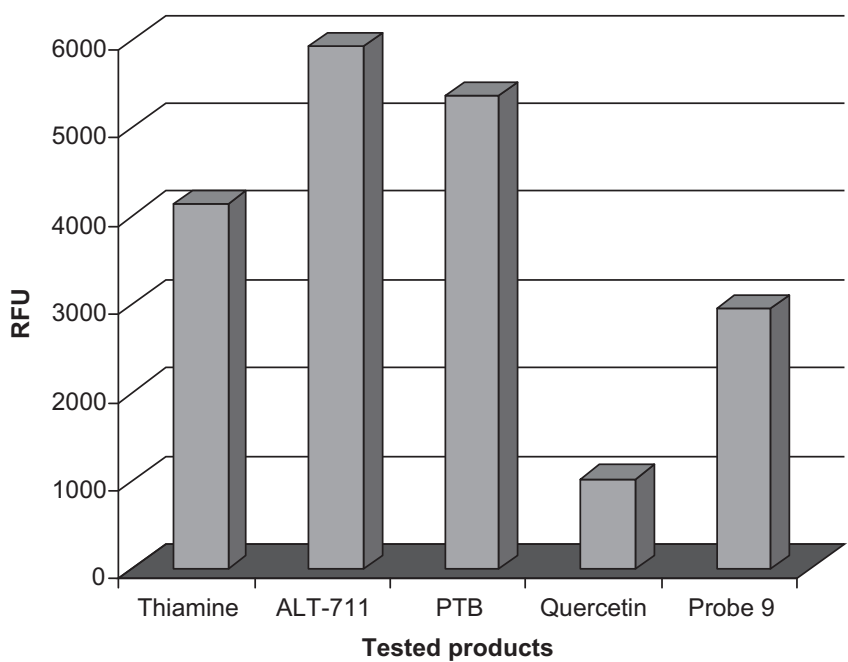

Figure 8. Formation of 1-naphthoic acid from probe $\mathbf{9}(22 \mathrm{mM})$ and tested product $(10 \mathrm{mM})$ in DMSO/phosphate buffer $\mathrm{pH} 7.4(1: 1,100 \mu \mathrm{L})$ incubated for $3 \mathrm{~h}$ at $37{ }^{\circ} \mathrm{C}$ measured by fluorescence ( $\lambda_{\mathrm{exc}} 280 \mathrm{~nm}, \lambda_{\mathrm{em}} 385 \mathrm{~nm}$ ) on a microplate reader. When tested products were AGEs breakers as PTB, ALT-711 or thiamine, an increase in fluorescence was observed.

As shown on Figure 7, in aqueous media, probe $\mathbf{9}$ is degraded in 1-naphthoic acid but this reaction occurs faster and with a best yield when an AGEs breaker is added.

As shown on Figures 6 and 7, when this assay to detect AGEs breakers ( $10 \mathrm{mM}, 1$ equiv) using probe $\mathbf{9}(22 \mathrm{mM}, 2.2$ equiv) was performed in a mixture DMSO/phosphate buffer $\mathrm{pH} 7.4$, formation of fluorescent 1-naphthoic acid could be checked after $3 \mathrm{~h}$ at $37{ }^{\circ} \mathrm{C}$ using HPLC-UV as well as a fluorescence microplate reader $\left(\lambda_{\text {exc }} 280 \mathrm{~nm}\right)$. As illustrated by Figure 8 , it allows detection of well-known AGEs breakers such as ALT-711 2 or thiamine and discriminates AGEs breakers from AGEs inhibitors such as quercetin. $^{28}$

Naphthoic acid derivatives, particularly probe $\mathbf{9}$, described in this work allow the simple and rapid detection of AGEs breakers using a 96-well microplate fluorescence assay. To our knowledge, since the inaugurate publication about AGEs breakers ${ }^{12}$ whose activity was demonstrated using HPLC analysis, it is the first publication about an assay suitable for automated and high throughput screening of AGEs breakers. Further improvements of this assay are currently under investigations: one of them consists in naphthoic acid analogs immobilization on glass support to allow rinsing steps and avoid fluorescence quenching phenomena due to evaluated substances.

\section{Acknowledgments}

This work was supported by Grants from la region Pays de la Loire (PROVASC) and University of Angers. The authors thank B. Siegler and Dr. I. Freuze for their assistance in NMR spectroscopy and MS 'respectively'.

\section{Supplementary data}

Supplementary data (synthesis protocols, compounds data and analytical procedure) associated with this article can be found, in the online version, at http://dx.doi.org/10.1016/j.bmcl.2012.08. 092 .

\section{References and notes}

1. Singh, R.; Barden, A.; Mori, T.; Beilin, L. Diabetologia 2001, 44, 129.

2. Brownlee, M. Nature 2001, 414, 813.

3. Takeuchi, M.; Yamagishi, S.-I. Curr. Pharm. Des. 2008, 14, 973.

4. Jandeleit-Dahm, K.; Cooper, M. E. Curr. Pharm. Des. 2008, 14, 979.

5. DeGroot, J. Curr. Opin. Pharmacol. 2004, 4, 301.

6. Grillo, M. A.; Colombatto, S. Amino Acids 2008, 35, 29.

7. Reddy, V. P.; Beyaz, A. Drug Discov. Today 2006, 11, 646.

8. Khalifah, R. G.; Baynes, J. W.; Hudson, B. G. Biochem. Biophys. Res. Commun. 1999, 257, 251.

9. Monnier, V. M. Arch. Biochem. Biophys. 2003, 419, 1.

10. Nagaraj, R. H.; Shipanova, I. N.; Faust, F. M. J. Biol. Chem. 1996, 271, 19338.

11. Biemel, K. M.; Lederer, M. O. Bioconj. Chem. 2003, 14, 619.

12. Vasan, S.; Zhang, X.; Zhang, X. N.; Kapurniotu, A.; Bernhagen, J.; Teichberg, S.; Basgen, J.; Wagle, D.; Shih, D.; Terlecky, I.; Bucala, R.; Cerami, A.; Egan, J.; Ulrich, P. Nature 1996, 382, 275.

13. Vinson, J. A.; Howard, T. B. J. Nutr. Biochem. 1996, 7, 659

14. Derbré, S.; Gatto, J.; Pelleray, A.; Coulon, L.; Séraphin, D.; Richomme, P. Anal Bioanal. Chem. 2010, 398, 1747.

15. Vasan, S.; Foiles, P.; Founds, H. Arch. Biochem. Biophys. 2003, 419, 89.

16. Cheng, G.; Wang, L. L.; Qu, W. S.; Long, L.; Cui, H.; Liu, H. Y.; Cao, Y. L.; Li, S. Acta Pharmacol. Sin. 2005, 26, 1460.

17. Cheng, G.; Wang, L. L.; Long, L.; Liu, H. Y.; Cui, H.; Qu, W. S.; Li, S. Br. J. Pharmacol. 2007, 152, 1196.

18. Pathak, P.; Gupta, R.; Chaudhari, A.; Shiwalkar, A.; Dubey, A.; Mandhare, A. B.; Gupta, R. C.; Joshi, D.; Chauthaiwale, V. Eur. J. Med. Res. 2008, 13, 388.

19. Haugland, R. P. Handbook of fluorescent probes and research products; Molecular Probes: Eugene, 2002.

20. Pompella, A.; Comporti, M. Am. J. Pathol. 1993, 142, 1353.

21. Schalk, M.; Batard, Y.; Seyer, A.; Nedelkina, S.; Durst, F.; WerckReichhart, D. Biochemistry 1997, 36, 15253

22. Kim, Y.-S.; Kim, S.-H.; Son, Y.-A. Mol. Cryst. Liq. Cryst. 2010, 519, 90.

23. Liu, J. M.; Zheng, Q. Y.; Yang, J. L.; Chen, C. F.; Huang, Z. T. Tetrahedron Lett. 2002, 43, 9209 .

24. Bailey, D.; Murphy, J. N.; Williams, V. E. Can. J. Chem. 2006, 84, 659

25. Thornalley, P. J.; Minhas, H. S. Biochem. Pharmacol. 1999, 57, 303.

26. Dewick, P. M. Essentials of organic chemistry: For students of pharmacy, medicinal chemistry and biological chemistry; John Wiley \& Sons: Chichester, 2006.

27. Fluorescence quantum yields of 0.04 and 0.13 were determined at $20^{\circ} \mathrm{C}$ respectively for probe $\mathbf{9}$ and 1-naphthoic acid in EtOH by using anthracene as a standard.

28. Ferchichi, L.; Derbré, S.; Mahmood, K.; Touré, K.; Guilet, D.; Litaudon, M.; Awang, K.; Hadi, A. H. A.; Le Ray, A. M.; Richomme, P. Phytochemistry 2012, 78, 98. 